\title{
Developing digital fieldwork technologies at the British Geological Survey
}

\author{
Colm J Jordan* \& Bruce Napier \\ ${ }^{1}$ British Geological Survey, Environmental Science Centre, Nicker Hill, Keyworth, \\ Nottingham, NG12 5GG, UK. \\ *Corresponding author (e-mail: cjj@bgs.ac.uk)
}

\begin{abstract}
Geological Surveys are faced with budget constraints and calls for efficiency gains; the effective application of digital techniques is often seen as a route to meeting these demands while increasing the value of outcrop studies and reducing the inherent subsurface uncertainty. The British Geological Survey may be the oldest national Survey in the world (established in 1835), however developing and implementing new, innovative and efficient technologies for fieldwork is a high priority. Efficient tools for capturing, integrating, manipulating and disseminating outcrop data and information are imperative to enable geoscientists to increase their understanding of geological processes and therefore to reduce subsurface uncertainty and risk. Systems for capturing structured digital field data and for visualising and interacting with large datasets are increasingly being utilised by geoscientists in the UK and internationally. Augmented reality and unmanned aerial vehicles are amongst the developing technologies being explored for future operational implementation. This paper describes the digital field mapping (BGS-SIGMAmobile) and visualisation (GeoVisionary) systems and refers to a case study outlining their contribution to reducing uncertainty and risk in hydrocarbon exploration.
\end{abstract}

\section{Introduction}

Geological Surveys including the British Geological Survey (BGS) have primarily utilised conventional analogue mapping techniques until relatively recently. Analogue field techniques had changed little since the original days of fieldwork by pioneers such as William Smith who created the geological map of Britain in 1815. Smith documented his field records in a notebook and marked symbols and linework on paper fieldslips in much the same way as mapping geologists did until very recently. The continuing prevalence of paper techniques was highlighted as recently as 2007-when the fourth edition of "Basic Geological Mapping” (Barnes \& Lisle 2007) listed the field equipment that a geologist should possess, and described in detail the type of field notebook that is recommended i.e. "it should have good quality 'rain-proof' paper, a strong hard cover and good binding" whilst "at least three pencils are needed". There is no mention of digital field mapping techniques or the prospect of their introduction in the future, although current educators are trying to address this (e.g. England et al. 2010; Pavlis et al 2010). BGS has endeavoured to develop and apply technological solutions to geoscience data and visualisation challenges; systems such as BGS·SIGMAmobile and GeoVisionary are providing solutions to geoscientists for data acquisition, field mapping, and data visualisation.

\section{Developing a Digital Field System}

Digital field mapping has been an aim of Geological Surveys for many years (Brodaric 1997; De Donatis \& Bruciatelli 2006; Farrant et al. 2001). The concept is that the process of acquiring digital data in the field would have several benefits including increased efficiency 
for capturing, manipulating, integrating, understanding and disseminating field and outcrop data. Specific gains should include i) ensuring obligatory data collection - guaranteeing that vital data (e.g. location information such as map grid reference) is collected either manually, or automatically from a GPS; ii) standardised recording - making sure that the same sets of data are collected by each member of a field team at each outcrop; iii) using standardized nomenclature e.g. making use of drop-down menus where appropriate so that field teams are constrained to standard dictionaries such as the "Munsell Color" chart for recording colour; iv) enabling inter-operability with other data e.g. structure data collected in the field can be used on-the-fly to create structure contours; v) the system should allow access to 'prior information' that results in 'smarter mapping' e.g. aerial / satellite imagery, existing geological fieldslips, geophysics data etc. (Jordan et al 2005).

Furthermore, rather than simply replicating the tasks that can be completed with the analogue pen/paper/map routine, the digital system must offer additional functionality. Examples of this include the ability to enter a dip/strike measurement and to automatically create structure contours using an underlying DTM, or to provide the facility to compile all of the field data collected (text, measurements, photos etc.) into an MS Word report. Crucially, the field system must provide an efficiency gain. Time may not necessarily be saved at the outcrop, however transferring validated digital field data directly to corporate databases allows more time for manipulation and modelling rather than transposing / digitizing, which takes resources at the office and can also potentially lead to errors.

In 2001, BGS published the user requirements for digital field data collection (Farrant 2001). The specifications document outlined in broad terms what the system should collect would not only collect point structural geological data, but would also collect the full range of data required by a Geological Survey including Quaternary geology, landform descriptions, landslide pro formas, photographs etc. The system should be constrained by dropdown menus or tick boxes where appropriate to save time, but must also provide the functionality to draw sketches and write 'free text' so that the process of field mapping would not be constrained or that some data could not be collected or that mapping became a 'box ticking' exercise rather than a meaningful scientific endeavour. Ultimately, it was vital that the system was developed with significant input from field geoscientists, who are the end users.

BGS first explored the concept of digital field data collection in 1989, with the conclusion that the mobile computing hardware at that time was not suitable. The development was therefore postponed. External reviews of BGS such as Walton and Lee (2001) recommended revisiting the prospect of digital field mapping and in the same year an international workshop on digital field data capture was hosted by BGS in the knowledge that other organisations such as the Geological Survey of Canada had also begun to explore digital field mapping (Brodaric, 1997). North American and European Geological Surveys attended and presented the status of mapping systems, if they existed, in their countries. Similarly, software and hardware suppliers were invited to demonstrate their products. At that time, the available systems were capable of limited point data capture using Personal Digital Assistants (PDAs) and as this was not sufficient for BGS geoscientists, the organisation set about designing and developing a bespoke system (Jordan, 2009). 
In 2001 BGS started testing Husky fex21 hardware with the PocketGIS ${ }^{\circledR}$ software primarily for a granite and landscape mapping project in the Cairngorm Mountains of Scotland (Thomas et al 2004). Challenges with the hardware (primarily related to the battery life and screen quality) resulted in a move to PDAs operating Windows CE ${ }^{\mathrm{TM}}$ in the same year. A customized version of ESRI ArcPad ${ }^{\mathrm{TM}}$ served as the front end, whilst a bespoke BGS eMbedded Visual Basic (eVB) application containing hard-coded data structure links in a compact database format was used to collect and hold additional relational data that would otherwise have been stored in the geoscientists notebook. Hierarchical input forms were constructed to collect various levels of data; index level data were added for each field site and an "Open Notebook" button gained access to more detailed forms for various mapping modules. At the time, similar systems were in development in the U.S. (Pavlis and Little, 2001). The small screen size of the PDA (approx 6 × $8 \mathrm{~cm}$ ) was sufficient to display a small map area along with the user's position, which was derived from a Global Positioning System (GPS) grid reference that was served via a Bluetooth device. The field staff were equipped with a 'digital toolbox' containing the PDA, a Bluetooth GPS, a digital camera and various accessories.

Whilst this was a significant advance from a paper field system, the screen size was a major limiting factor. While it was arguably sufficient for point sample collection, feedback from the majority of field geologists stated that it was not suitable for geoscientists working with maps. The screen was too small to visualize enough of the mapface to gain spatial context, and furthermore, annotating the visible area of the maps with lines, polygons and text proved problematic because scrolling beyond the current view was required to delineate even the smallest of landscape features. Furthermore, each release of new PDA hardware (BGS was primarily using the Hewlett Packard iPAQ platform) brought Open CE updates which often required time-consuming modifications to the eVB code. Clegg et al (2006) came to the same conclusion when comparing tablet PC and PDA hardware, stating that the tablet devices were more suitable for a wide range of geological data collection tasks when using their "MAP IT" software. Nevertheless, some organisations adopted the small screen size devices and still like them for their ease of portability (Pavlis pers comm, 2015).

Fortuitously, by 2002, the first rugged tablet PCs entered the market, and while the early incarnations were too expensive to equip field teams and often too heavy to carry for long periods ( $>2.5 \mathrm{~kg}$ ), they provided a solution to both the screen size and the operating system issues. BGS began experimenting with, and developing software for, tablet PCs in the expectation that the hardware would become more widely available, more affordable and more fit-for-purpose. By 2004 the software was migrated to a ruggedised tablet PC system operating on Microsoft XP for Tablet Edition. Training courses for staff in this new 'BGS·SIGMAmobile' (System for Integrated Geoscience Mapping) began in 2005 (Fig. 1). At this time, a similar digital field system (GeoMap) was also being developed in the U.S. on tablet PCs based on the Strata Software's PenMap (Birmhall et al 2002).

BGS.SIGMAmobile is a heavily customized version of ESRI ArcMap as the front-end with relational data held in a bespoke MSAccess2007 database. Additional functionality is provided by linking modified versions of InkWriter (software that enables handwriting recognition). Software development of BGS·SIGMAmobile system was done using a 
variety of languages including VBA and .NET. With each new release of ESRI software, BGS has also updated the field system and it currently operates with ArcMap10.1.

BGS·SIGMAmobile is an integrated field system that enables a broad array of geoscientific data to be recorded using tick boxes, sketches, drop-down lists, tagged free text, and photographs where appropriate (Fig. 2). Spatial location and navigation is managed by built-in GPS whilst the stylus enables points, lines, polygons, and comments to be added to the digital map face. As with the preceding PDA system, additional relational information is added using customized forms and a selection of interfaces. The system is modular, with tabs for various themes or domains of geological data such as structural readings, landslides information and auger/section recording etc. Furthermore, there are additional tools including the ability to draw sketches, annotate photographs, produce structure contours, and navigate using bearings. All of the data collected in BGS.SIGMAmobile are tagged with a Unique User IDentifier (UUID) enabling them to be queried and tracked through corporate repositories.

It has been proposed that the preference in geological mapping is to interpret observations during the mapping process (Jones et al. 2004; McCaffrey et al. 2005) however BGS·SIGMAmobile primarily records observations, separate from interpretations, in order to improve traceability in the derived outputs and to separate, where possible, observed data with interpreted information. It is expected that this increases confidence in the data and therefore reduces the uncertainty of the derived maps and models.

A choice of tools for adding text, lines, and polygons to the map face is provided, ranging from a basic tool that replicates the pencil and paper routine through to tools that enable topologies and attributed lines to be created in the field. Advanced handwriting software is used extensively to deliver legible field notes (even on the map face), however cursive text can still be used for rough notes where appropriate. Drop-down menus and tick boxes are used where possible and efficient to ensure that entries conform to accepted standards and that the agreed nomenclature is used. Areas for free-form text are also provided to allow flexibility. Novel systems have been developed and employed to ensure that the data recorded is unambiguous; e.g., rather than asking a geologist to tick a box to note if they are using the right hand rule when recording a structural measurement, a compass is provided which is ticked to identify the dip direction. This reduces confusion regarding how the data were recorded.

The tablet PC hardware was a challenge for the early releases of the system, e.g. weight, screen visibility in bright light and shorter-than-advertised battery life. However technology has advanced and platforms now exist that are generally suitable for use in the field by geoscientists. Following trials with a SunscreenPC in 2001, the favoured hardware was the Itronix GoBook and, subsequently, the GoBook DuoTouch followed by the Xplore iX104 series, the GETAC V100 and currently the Panasonic ToughPad. Pavlis et al (2010) record a similar history of equipment trials. Non-rugged systems are also available, such as the Microsoft SurfacePro. In general the non-rugged systems are lighter and cheaper, but their screens are not as readable in variable light conditions, and they are more prone to everyday wear-and-tear and fatal damage from water/dust ingress and from drops and knocks. There are a range of ruggedness ratings e.g. IP54 or IP67, so there is a choice to make 
between the level of hardware resilience required and the cost the organisation is willing to pay. There is an option to use a non-rugged system and to use a weather-proof case.

While BGS·SIGMAmobile was originally designed purely as a data collection tool, a significant part of its power and functionality comes from the ability to bring a wide range of data (e.g. satellite imagery, aerial photography, geophysical data, historic field slips and topographic maps) to the field. This has also been recognized elsewhere e.g. Carver et al (1995) when a Geographic Information System (GIS) was used in the field. This improved access to data and information in the field significantly increases the knowledge-based decisions of the geologists, leading to reduced uncertainty in the data collected and the information derived from it.

Aside from bedrock and Quaternary geologists, the ability to record features such as landslides, dimension stone information and mine information has broadened the user base significantly (Evans et al 2013; Jordan 2010; Jordan \& Pennington 2011).

In 2009 BGS·SIGMAmobile was released at no cost to both academic and commercial users, downloadable from the BGS website. The premise for free distribution was to promote its use and to encourage the growth of a developer community. The only stipulation prior to download is that new developments must be supplied to BGS for inclusion in subsequent free releases. This free release has led to the use of the system for teaching in university departments (e.g. England et al 2010) and also by other Geological Surveys (e.g. Henderson \& Guilio 2011). Over 2000 licenses have been downloaded worldwide. The system also gained recognition when it won the 2007 ESRI Central Government GIS Excellence Innovation Award.

The BGS·SIGMAmobile system was the sole component in the first two releases, however the version released in 2013 integrated the BGS·SIGMAdesktop functionality that had previously not been released outside BGS. This provides tools for routine transformation of field data into corporate standard geological models and derivative map outputs. Development of the system is still ongoing as a result of both user feedback and the changing face of technology. Investigations into the development of a BGS·SIGMA smartphone app are currently taking place alongside system developments such as a new and more streamlined data entry system.

\section{UAV field data collection}

A growing area of interest internationally is the capability of collecting geoscience field data using Unmanned Aerial Vehicles (UAVs), also called Unmanned Aerial Systems (UAS) or Remotely Piloted Aerial Systems (RPAS). It is argued here that UAVs can be considered as field data acquisition systems because the equipment can be taken to a field site in a standard vehicle (or in a rucksack, depending on the system) and generally operated by a geologist, with suitable safety and regulatory training. In this respect it is no different from routine geoscience instruments such as terrestrial laser scanning, and in fact the latest UAV systems incorporate laser scanning technology.

UAVs, in the form of parafoils have been used in BGS since 1986, and in the last ten years these have been added to with kites, fixed wing and rotary systems (Hobbs et al. 2010). 
The use of ground control and differential GPS ensures that calibrated and validated outputs can be delivered including orthorectified aerial photography, point clouds, triangular irregular network (TIN) models and gridded elevation models. Desktop software using structure for motion (sfm) technology has put stereo aerial photography processing and DEM extraction in the hands of the masses. Elevation / motion and volume changes can be calculated e.g. for landslides, and BGS is now routinely using UAV technology to acquire multi-temporal data over landforms such as landslides (Fig. 3). RGB cameras are now the 'elder statesman' of sensor systems on UAVs while multispectral and thermal cameras are becoming ubiquitous. Miniaturized sensors such as laser scanners, gas monitors and geophysical equipment are breaking into the commercial market and their systematic use will significantly expand the data collection opportunities available in the field at this scale.

\section{Developing a Virtual Field Reconnaissance System}

The BGS Virtual Field Reconnaissance (VFR) project was developed to allow geologists to immerse themselves in a virtual landscape providing the ability to 'bring the field into the office'. Teams gather in an immersive virtual environment and discuss complex field outcrops, followed by fieldwork focused on addressing specific issues that have arisen in the office.

The initial challenge set for the VFR project was to build on existing project-based virtual field trip and geoscience visualisation applications, that had been created by BGS during and after the Digital Geoscience Spatial Model programme from 2000 to 2004 (Riddick et al 2005), and to create systematic efficiency gains in fieldwork. Primarily, this would be achieved through use of newly acquired national high resolution datasets, such as the Nextmap Great Britain 5m Digital Surface Model and 5m Digital Terrain Model, and aerial photography, along with the wealth of digital geological data held by the BGS. A Virtalis Activewall single channel active stereo visualisation system, known in BGS as the immersive 3 Dimensional Visualisation Facility (i3DVF) is used by teams while the system can also be used by individuals on their PCs (or a suitably equipped laptop) to ensure that virtual fieldwork is available to all BGS geoscientists.

In a review of existing software with 3D visualisation capability such as ESRI, Google and NASA, or 3D geological modelling software like GOCAD and GSI3D, BGS staff decided that no single software package could meet the user requirement for a BGS VFR system. Essential elements of the user requirement that could not all be addressed by any one of those software packages included handling the volume of data and graphics output on PC workstations, ease of use, use in the i3DVF, interaction with the virtual landscape and integration with BGS·SIGMA. BGS's solution was to work with Virtalis Ltd who adapted their engineering model visualisation software to work with geoscience datasets and allow the user to interact with them to the VFR specification. The initial pilot version was judged a success so the project was continued, and since 2007 BGS and Virtalis Ltd have worked together to create commercially available software for visualisation and interpretation of large geospatial datasets from multiple sources. That software, GeoVisionary, which was first released in July 2008, allows users to visualise terabytes of surface and subsurface data in high powered immersive 3D visualisation systems, as well as on desktop PC's and 
laptop workstations.

GeoVisionary provides tools for digitising points, poly lines and polygons which allow the user to map geological features limited only by the resolution of the terrain model and imagery. Lighting angles can be changed to help identify features from the virtual terrain. Structural measurements from oriented planes can be drawn in three dimensions, calculated from three points picked from the terrain model. The user can compare the existing geological interpretation of an area with that gained from the virtual environment and decide whether or not they agree with that interpretation and therefore make better decisions on where to target field work. All of the data collected in GeoVisionary can be saved as ESRI 3D shapefiles for use in GIS and 3D modelling software.

BGS created custom software for ESRI ArcMap, the Arc2GV Toolbar, which links GeoVisionary on the i3DVF PC and BGS.SIGMA on a tablet PC. Location data, sent wirelessly from GeoVisionary, is used by BGS·SIGMA to match the 2D GIS view with the virtual landscape. The data collected in the virtual field environment is immediately transferred to the BGS.SIGMA device with the Arc2GV Toolbar and can be taken directly to the field. On return from fieldwork, the Arc2GV link is restored and the newly collected data from the field can be visualised and interpreted in the i3DVF. Using virtual reality, fieldwork and GIS together in this way, has been shown to bring better quality results from time spent in the field, increase the accuracy of interpretation and help build better team understanding, communication and confidence (Ford et al, 2013). A degree of computer literacy is required by the users of the system, and it is strongly advised to back-up one's work in case of equipment failure or loss.

Virtalis have developed a streaming data engine, fully utilizing the latest graphics card technology from nVidia that has helped to overcome one of the biggest technological problems in geoscience visualisation: how to smoothly visualize huge data volumes of multiple resolution data in a convincing virtual reality environment. It goes a long way towards answering many of the problems with multi-scale geoscience model visualisation identified by Jones et al (2008). In 2012 visualisation of LiDAR point cloud data and volumetric (voxel) models was added to the GeoVisionary functionality list. The volume and density of terrestrial LiDAR has rapidly increased in recent years. In response, the point cloud capability was increased in 2014, enabling visualisation and interpretation (measuring, digitizing, structural measurement) of billions of points, simultaneously with all of the other data in a single GeoVisionary project (Fig. 4).

\section{Case Studies}

Published case studies describe the use of the BGS digital systems for field mapping in terrains such as the UK (Evans et al 2013 and Leslie et al 2014) Ghana, Madagascar and the United Arab Emirates ( ${ }^{1}$ Jordan 2010), Norway (Henderson and Guilio, 2011) and petroleum exploration in Tajikistan (Jordan et al 2009). These studies have highlighted how the systems have been applied to various BGS mapping projects and also by geologists from other organisations. Experience from the case studies has demonstrated that time at the outcrop is often limited (due primarily to cost) and it is desirable to derive the most value from fieldwork e.g. by (i) having as much appropriate ancillary data to 
hand as possible to promote more informed decision-making in the field, (ii) ensuring that geologists collect the full suite of mandatory data at each outcrop, (iii) standardising the nomenclature that is used, (iv) providing on-the-fly functionality such as deriving structure contours. All of these factors contribute significantly to reducing uncertainty in the decisions made at the outcrop. The BGS studies also highlight that a well-documented workflow is a prerequisite in order to ensure that i) adequate preparation of data prior to fieldwork, because it is often not possible to have data sent to the field area if it has been forgotten, ii) staff fully trained in the use of the systems, iii) protocols for data transfer, manipulation and long-term management / storage.

It has also been demonstrated that the large amount of data now available to geologists using digital techniques in the field, along with the capacity to collect new structured digital data, makes the "field mapping process much more efficient and increases the reliability and repeatability of collected data” (Pavlis et al 2010).

The case studies above emphasize the impact that new technologies have made to geological mapping, and how they have contributed to reducing uncertainty. The Tajikistan case study (Jordan et al 2009) specifically relates to outcrop studies for petroleum exploration undertaken by Tethys Petroleum and BGS when a Production Sharing Contract (PSC) was signed and a short timescale was available to start exploration drilling in the 40,000 square kilometer Bokhtar area. GeoVisionary was used to compile a 3D model using existing conventional oil company data in the area, consisting of mainly elderly Soviet era geological maps, well logs and very sparse dubious seismic, all on paper. Tethys had 18 months for the initial phase of geological studies, seismic acquisition and reprocessing, and field rehabilitation trials, with exploration drilling in the second 18 month phase and a first relinquishment after 7 years. Remote sensing data were acquired and analysed in order to study the large remote area efficiently. They were used to plan field geology and seismic acquisition in order to complete the first phase of the exploration programme on time. A model was built in GeoVisionary from Landsat images, SRTM and DTM data, and loaded into the 3D visualisation facility for stereo viewing by the team of BGS and Tethys geologists. The geological and structural model was further improved using higher spatial and spectral resolution ASTER satellite imagery. Cross sections were prepared and seismic and well logs incorporated where appropriate.

A reconnaissance field trip assessed the quality of this remote work and identified areas of specific interest for the remainder of the exploration work programme. As part of the reconnaissance, seismic lines were planned and the routing was checked in the field using BGS.SIGMAmobile. Outcrops encountered in the field were recorded in the digital system, and information from them was fed back into the 3D model. The combination of the pre-field 3D visualisation and the digital field data allowed Tethys to conduct their exploration on schedule and to plan the seismic campaign with confidence (Jordan et al 2009).

It is fitting to re-evaluate the Tajikistan case study in light of new technologies and to consider what might be done differently now. Firstly, UAV technology was not widely available in 2008 and therefore they were not incorporated into the project. The 
technology is readily available today to collect a suite of site-specific high resolution data including stereo aerial photography, thermal, hyperspectral, geophysical and LiDAR data. The field tablet PCs have reduced in weight and increased in processing and graphics power, so not only can they be used to collected data, but those data can be visualised at the outcrop using augmented reality such as iGeology 3D (http://www.bgs.ac.uk/igeology/3d.html). 3D visualisation systems, such as GeoVisionary are now able to incorporate a wider range of datasets such as 3D point clouds and multiscalar DTMs, enabling the geologist to add more detail to the mapping and further reduce the outcrop uncertainty. It is debatable whether the digital field mapping systems have encountered a step-change in technology since 2008, however the user interfaces are more streamlined, the systems are more stable (hardware and software), and the protocols to prepare and manage the data are more complete. The range of visualisation and digital mapping systems now on the market is testament to their increased integration into routine mapping.

\section{Discussion \& Conclusions}

The strategy for most Geological Surveys (including BGS) has been to develop and implement digital systems that increase our understanding of the subsurface and to move from printing paper geological maps to delivering focused outputs such as 3D and 4D models. Validated digital field data capture provides a streamlined route for populating corporate databases, from which an array of outputs can be delivered including paper/digital maps, 3D models and smartphone applications.

The culture of geoscience field mapping has changed in Geological Surveys, and the introduction of digital field systems has had a large input to this (Jordan et al 2008). It is generally accepted that field mapping in Geological Surveys encompasses, and benefits greatly from, digital techniques (Leslie et al. 2014; McCaffrey et al. 2005) and students are also benefiting from structured digital techniques (England et al. 2010 and Pavlis et al. 2010). Systems developed in BGS are helping to integrate and collect complex digital data in the field and subsequently to transfer those data immediately and efficiently to corporate databases thereby making them instantaneously available for downstream uses such as 3D modelling (Henderson \& Guilio 2011).

Visualisation systems are also bringing field sites into the office and ensuring best use of geologists' time through virtual field reconnaissance prior to and post fieldwork. Time spent waiting for computers to load / transfer spatial data for geographic areas of interest has been reduced; GeoVisionary has advanced geoscience visualisation technology by placing large volumes of data at the hands of the user in near real time. Resources are freed to focus on visualizing and interpreting huge volumes of raster and vector data in a single environment rather than transferring them from archives or servers to visualize in separate software systems in i3DVF or on desktop PC workstations.

Digital data collection and visualisation has also been put into the hands of the public e.g. through smartphone applications such as myVolcano and iGeology (http://www.bgs.ac.uk/igeology/). Furthermore, the iGeology 3D application is an augmented reality system that projects 3D geology onto the smart phone screen, overlaid 
onto the landscape via the camera on the device. This new level of interaction with the data is currently used to promote geoscience to the public but can equally be used by professionals as an additional knowledge tool to decrease uncertainty at the outcrop.

The breadth of digital tools being made available to field geoscientists by a wide range of providers internationally is significant; for example ten years ago there were few integrated digital geological capture systems that had the functionality of point data recording and polygon mapping tools with an underlying relational database. Some of the credit for the arrival of digital mapping systems goes to the timely delivery to market of the rugged tablet PC; however the availability of the hardware is more than balanced by the foresight of those who developed software in the expectation that these types of hardware would become available.

Modern Geological Surveys also routinely utilize systems such as UAVs, although the differing levels of sensor use is still stark e.g. the contrast between a basic digital camera and a laser scanner. These systems are now delivering truly valuable data and their use is predicted to proliferate, although care must be taken to ensure that the systems are operated safely and that the results are calibrated and validated. Looking to the future, there is scope to further streamline the input systems; voice recognition is still under-used and the day will come when geoscientists will be able to verbally describe the outcrop and a digital system will tag the words and automatically populate the database, symbolize a map, and deliver the data back to base where it can be used instantaneously.

\footnotetext{
Sincere thanks are due to the dedicated team of GIS and database developers, for building the systems described here, and to Virtalis Ltd for co-developing the Geovisionary system. The constructive feedback from field geoscientists and the support of management throughout development and implementation is gratefully acknowledged. The authors thank two reviewers for their constructive comments. This paper is published with the permission of the Executive Director, British Geological Survey (NERC).
}

\section{References}

Barnes, J. W. \& Lisle, R. J. 2007 Basic Geological Mapping - Fourth Edition. Wiley, England.

Birmhall, G. H. Vanegas, A. and Lerch, D. 2002 GeoMapper program for paperless field mapping with seamless map production in ESRI ArcMap and GeoLogger for drill-hole data capture: applications in geology, astronomy, environmental remediation, and raised-relief models. In: Soller D R (ed) Digital Mapping Techniques 2002, U.S. Geological Survey Open-file Report 02-370.

Brodaric, B. 1997 Field data capture and manipulation using GSC FIELDLOG v3.0. In: Soller D R (ed) Digital Mapping Techniques: Methods for Geologic Map Capture, Management and Publication. US Geological Survey, Open File report, pp77-81. 
Calazans, P. P. Büchi, A Napier, B. Reinhardt, P. M. Orlandi, P. Dias, L. S. O. . Sistema Integrado de Mapeamento Geológico (SIGMA) com aplicação de realidade virtual e captura de dados digitais em campo. In: SIMEXMIN, 2014, Ouro Preto - MG. SIMEXMIN 2014, 2014

Carver, S. Heywood, S. C. \& Sear, D. 1995. Evaluating field-based GIS for environmental modelling, characterization and decision support. International Journal of Geographical Information Systems 9 (4), 475-486.

Clegg, P. Bruciatelli, L. Domingos, F. Jones, R. R. De Donatis, M. \& Wilson, R. W. 2006. Digital geological mapping with tablet PC and PDA: A comparison. Computers \& Geosciences 32 (2006) 1682-1698.

De Donatis, M. \& Bruciatelli, L. 2006. MAP IT: the GIS software for field mapping with a tablet PC. Computers \& Geosciences 32, 673-680

England, R. Smith, S. Tate, N. \& Jordan, C. J. 2010 Digital Geological Mapping for Earth Science Students. Vol 12 EGU 2010-2225, EGU General Assembly 2010.

Evans H, Pennington C, Jordan C J \& Foster C (2013) Mapping a nation’s landslides: a novel multi-stage methodology for landslide mapping and inventory within the UK. In C. Margottini et al. (eds), Landslides Science and Practice, Vol.1, DOI 10.1007/978-3-64231325-7_2. Springer-Verlag, Special Publication, Berlin Heidelberg 2013. pp21-27.

Farrant, A. R. Jordan, C. J. \& Thomas, C. W. 2001 A user requirement for Land Survey digital field data entry. British Geological Survey Internal Report, IR/01/137. 21pp

Ford, Jon; Dearden, Rachel; Napier, Bruce; Kessler, Holger. 2013 3-D visualisation at the British Geological Survey. [Lecture] In: GSA, Denver Annual Meeting, Denver, USA, Oct 2013. Geological Society of America. http://nora.nerc.ac.uk/503929/

Henderson, I. H. C. \& Guilio, V 2011 Implementering av digital berggrunnskartlegging ved Norges Geologiske Undersøkelse - NGU. Mineral Produksjon 1 (2011) 83-101.

Hobbs, P. R. N. Haslam, E. \& Jordan, C. J. 2010 Applications for UAVs at the British Geological Survey. Proc RSPSoc Annual Conference, Cork 2010.

Jones, R.R., McCaffrey, K. J. W., Clegg, P., Wilson, R. W., Holliman, N. S., Holdsworth. R. E., Imber, J. \& Waggott, S. 2009 Integration of regional to outcrop digital data: 3D visualisation of multi-scale geological models. Computers and Geosciences (2009), 35, 4-18.

Jones, R. R., McCaffrey, K. J. W., Wilson, R. W., \& Holdsworth. R. E. 2004. Digital field acquisition: towards increased quantification of uncertainly during geological mapping. In: Curtis, A. 7 Wood, R. (eds) Geological Prior Information. Geological Society, London. Special Publications, 239, 43-56.

Jordan, C. J., Bateson L., Bow J., Napier B. \& Johnson Sabine R. 2009 GeoVisionary ${ }^{\mathrm{TM}}$ 
software for 3D visualisation and petroleum exploration in southern Tajikistan. RSPSoc 2009 Annual Conference and Proceedings. http://nora.nerc.ac.uk/8854/.

Jordan, C. J. Bee, E. J. Smith, N. A. S. Lawley, R. S. Ford, J. Howard, A. S. \& Laxton, J. L. 2005. The development of Digital Field Data Collection systems to fulfil the British Geological Survey mapping requirements. In: Proceedings of the International Association of Mathematical Geology 2005: GIS and Spatial Analysis, Toronto. Vol. 2, pp886-891. http://nora.nerc.ac.uk/8434.

Jordan, C. J., Howard, A. S. \& Bee, E. 2008 The British Geological Survey digital field data capture system: better than pen and paper? Proceedings of the 33rd International Geological Congress, Oslo 2008. http://ww.cprm.gov.br/33IGC/1306002.html

${ }^{1}$ Jordan, C. J. 2010 BGS·SIGMAmobile; the BGS Digital Field Mapping System in Action. In: Soller D R (ed) Digital Mapping Techniques 2009, May 10-13 Morgantown West Virginia. U.S. Geological Survey Open-file Report 2010-1335.

${ }^{2}$ Jordan, C. J. 2010 A new era for digital geological mapping with the $2^{\text {nd }}$ release of the BGS digital mapping system. Geoconnexion: International. November 2010, Vol 9 Issue 10, pp44-35.

Jordan, C. J. \& Pennington, C. 2011 Digital field systems for landslides research; an insight from the latest British Geological Survey (BGS) product development. Geoconnexion UK, Vol 9, Issue 1. January / February 2011, p 8-9.

Lee, J. R. \& Booth, S. J. 2006 Quaternary field mapping: Lowland Britain. British Geological Survey Internal report, IR/06/099. 78pp. http://nora.nerc.ac.uk/7401/1/IR06099.pdf

Leslie, G. Smith, N. \& Jordan, C. J. 2014. Digital field mapping with the British Geological Survey. Geophysical Research Abstracts. Vol.16 EGU 2014-4172.

McCaffrey, K.J.W. Jones, R. R. Holdsworth, R. E. Wilson, R. W. Clegg, P. Imber, J. Holliman, N. \& Trinks, I. 2005. Unlocking the spatial dimension: digital technologies and the future of geoscience fieldwork. Journal of the Geological Society, London, Vol. 162, 2005, pp.927-938.

Pavlis, T.L. Langford, R. Hurtado, J. \& Serpa, L. 2010 Computer-based data acquisition and visualization systems in field geology: Results from 12 years of experimentation and future potential. Geosphere. June 2010, Vol. 6 No.3, p.275-294. Doi:10.1130/GES00503.1

Pavlis, T.L. and Little, J. 2001 Using handheld personal computers as field data collection tools: Some lessons learned in the school of hard knocks in the Wingate Wash project and related projects using Fieldlog/Field-worker software exported to ArcInfo. In Soller, D.R. ed Digital mapping techniques '01 Workshop Proceedings: U.S. Geological Survey OpenFile Report 01-233 p.115-122.

Riddick, Andy; Laxton, John; Cave, Mark; Wood, Ben; Duffy, Tim; Bell, Patrick; Evans, 
566 Chris; Howard, Andy;Armstrong, Bob; Kirby, Gary; Monaghan, Alison; Ritchie,

567 Calum; Jones, Dave; Napier, Bruce; Jones, Neil; Millward, David; Clarke, Stuart; Leslie, 568 Graham; Mathers, Steve; Royse, Kate; Kessler, Holger; Newell, Andy; Dumpleton,

569 Steve;Loudon, Vic; \&Aspden, John. 2005 Digital geoscience spatial model project final

570 report. Keyworth, British Geological Survey, 56pp. (BGS Occasional Publication No. 9).

571

572 Thomas, C. W. Gillespie, M. R. Jordan, C. J. and Hall, A. M. 2004 Geological structure

573 and landscape of the Cairngorm Mountains. Scottish Natural Heritage Commissioned

574 Report No.064 (ROAME No. F00AC103). 129p

575

576 Walton, G. \& Lee M. K. 2001 Geology for our Diverse Economy: Report of the

577 Programme Development Group for Onshore Geological Surveys. Keyworth, British

578 Geological Survey (NERC). ISBN 0852723865. 99p 
Fig. 1. (a) Digital field mapping training course and (b) digital field mapping in the United Arab Emirates.

583

584

585

586

587

Fig. 2. Sample Graphical User Interface to BGS·SIGMAmobile (a) ArcMap front end. (b) Top level forms for structured data capture. (c) Sub-form for collecting bedrock structural data. NEXTMap Britain elevation data from Intermap Technologies.

588

589

Fig. 3. Outputs derived from BGS UAV photography (a) Point cloud. (b) Textured

590 DEM derived. (c) 3D model of coastal landslide in 2013. (d) 3D model of same coastal 591 landslide in 2014.

593

Fig. 4. A terrestrial LiDAR scan of a cliff, consisting of more than 300 million points.

594 The red and green and cubes show where a point has been selected for digitisation as a poly-line. At the top of the image, distance, incline and bearing are shown as readings 596 


\section{$A$}

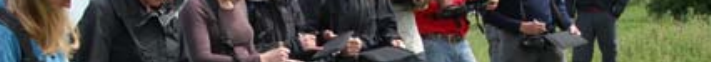

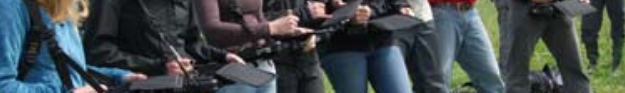
(6. a

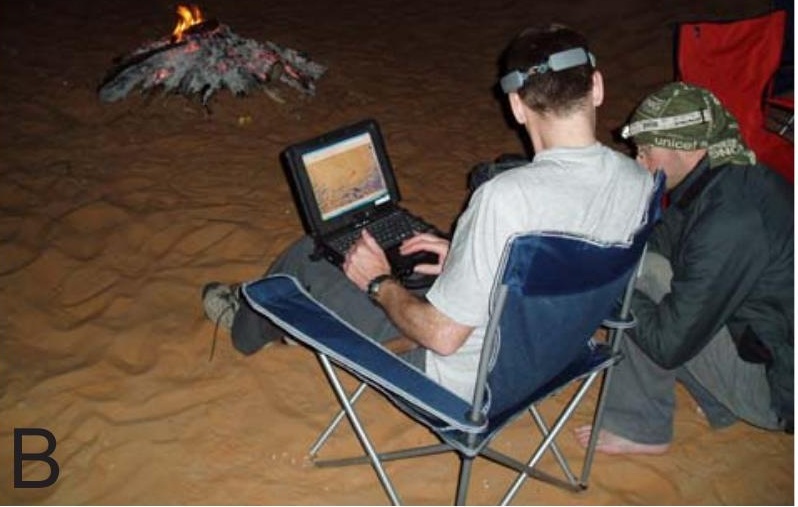




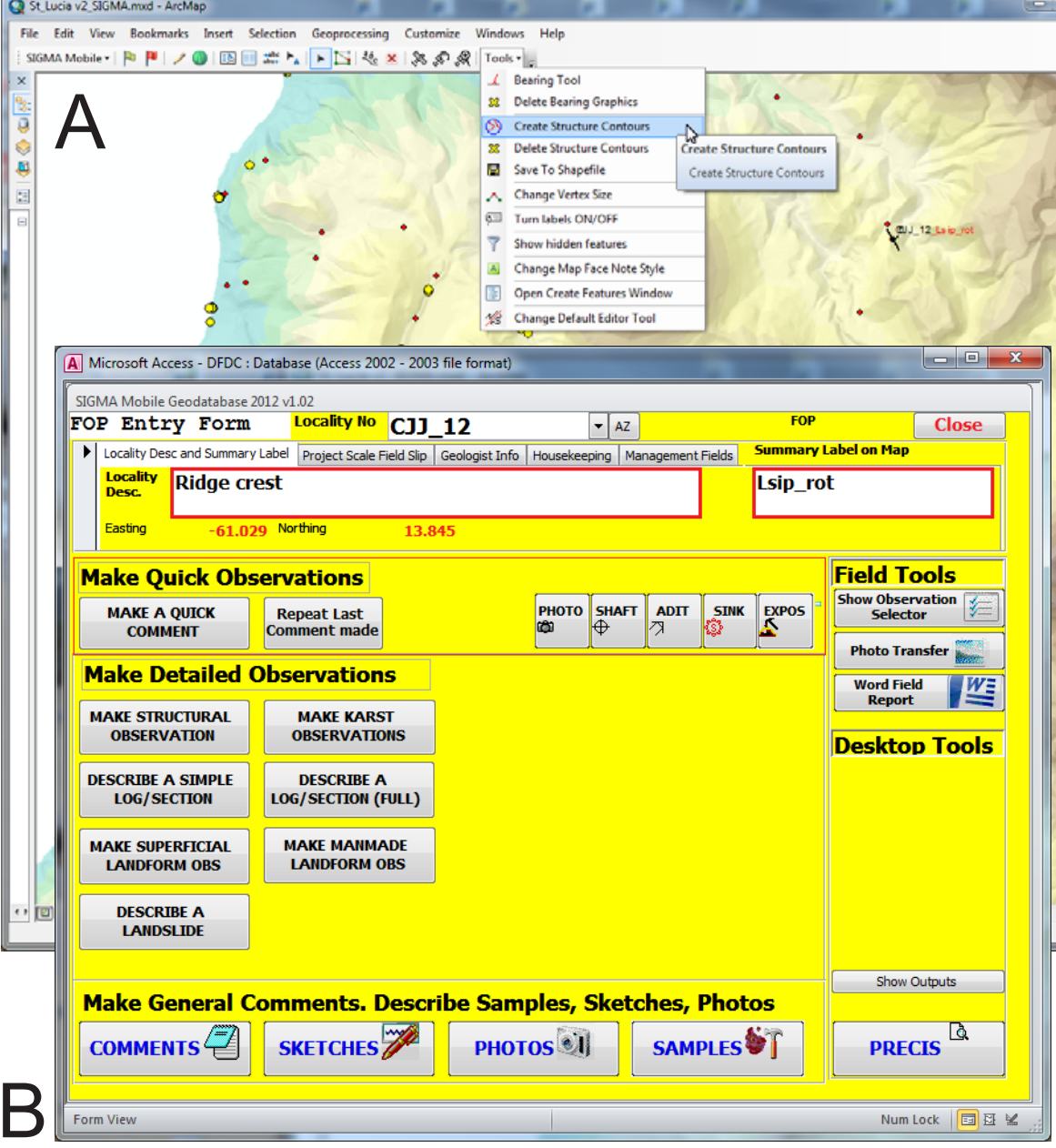

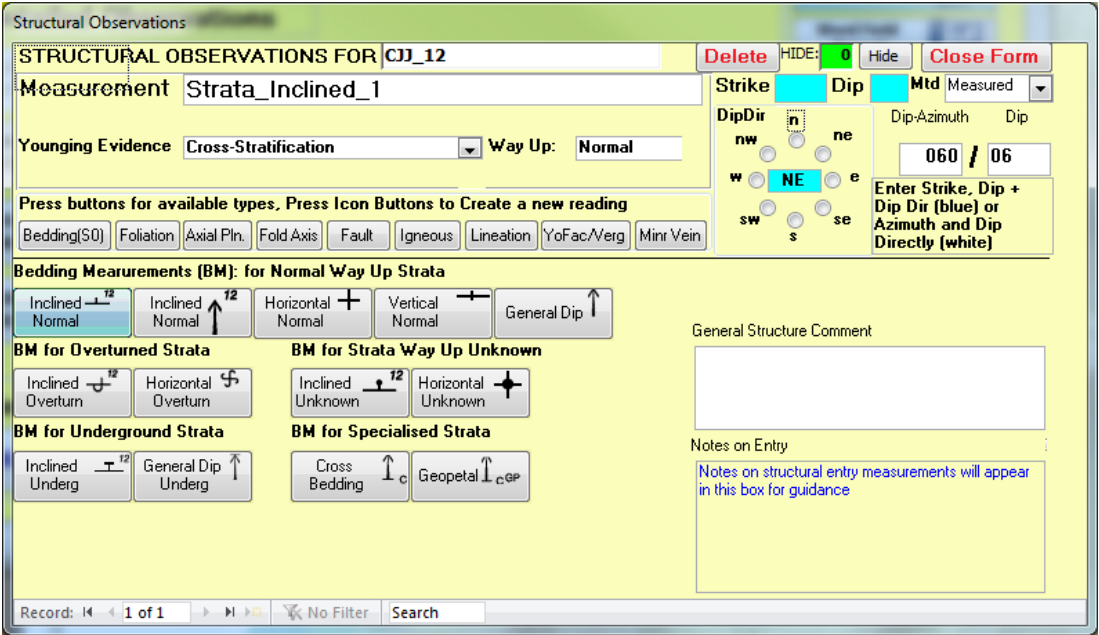




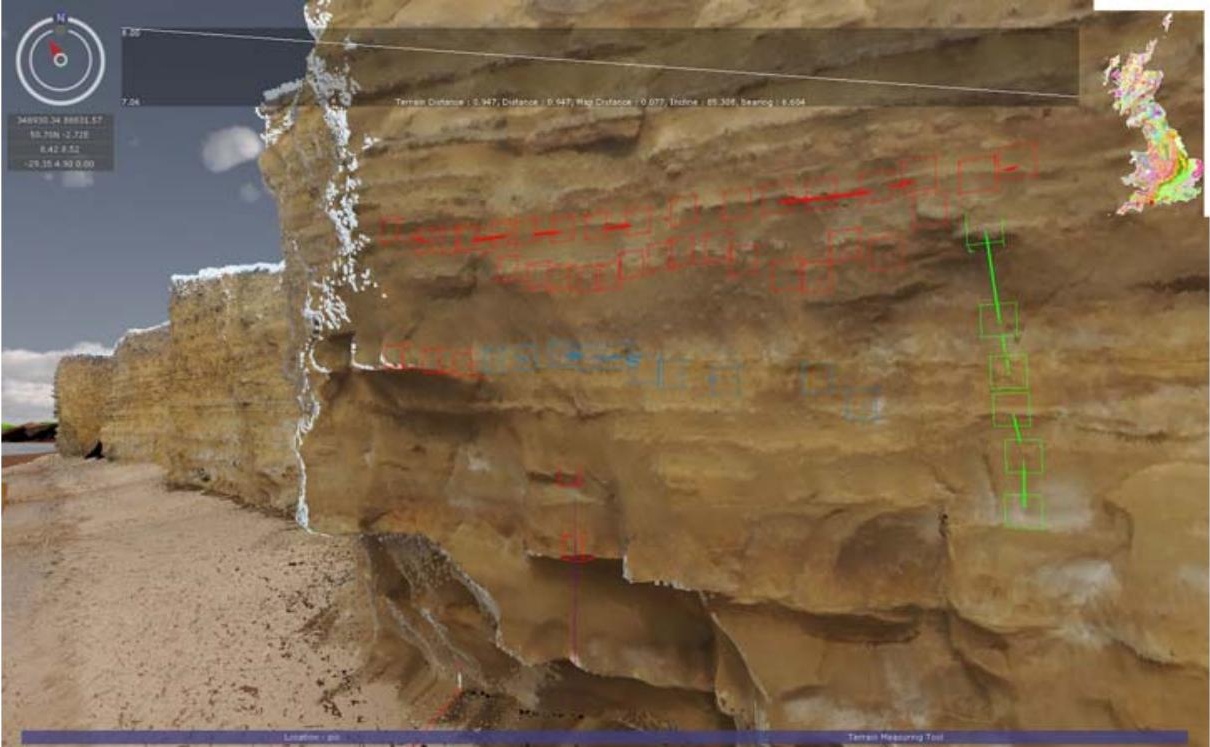

